\title{
Papež Frančišek in kardinal Kurt Koch o ekumenizmu danes. Dve ekumenski obletnici
}

\author{
Pope Francis and Cardinal Kurt Koch on Ecumenism \\ Today. Two Ecumenical Anniversaries
}

Drugi vatikanski cerkveni zbor (1962-1965) je prisluhnil Svetemu Duhu ter znamenju časa in se odločil za ekumenizem, kar je izraženo v odloku o ekumenizmu Pospeševati edinost (E) (Unitatis redintegratio /UR/), ki je bil slovesno razglašen 21. 11. 1964. Odloku se je kmalu, leta 1967, pridružil Ekumenski pravilnik (CD 53), ki ga je izdal Papeški svet za edinost kristjanov. Papež Janez Pavel II. je 25. maja 1995 izdal najpomembnejšo pokoncilsko ekumensko okrožnico Da bi bili eno (CD 63) (Ut unum sint /UUS/), ki je doživela številne pohvale in tudi delno zadržanost nekaterih nekatoliških kristjanov v svojih ocenah (Dolenc 1995, 11-21). Ob 40-letnici odloka o ekumenizmu, 11. 11. 2004, je kardinal Walter Kasper, predsednik papeškega sveta za edinost kristjanov, imel zelo odmevno predavanje o odloku o ekumenizmu Novo branje po štiridesetih letih na konferenci v mestu Rocca di Papa (2005, 73-87). Od ustanovitve Tajništva (danes Papeški svet), leta 1960, pa do danes je Katoliška cerkev naredila številne korake na področju duhovnega, teološkega in praktičnega ekumenizma, kar je v veliki meri v slovenskem jeziku spremljal strokovni ekumenski zbornik Vedinosti (prej Kraljestvo božje) in od leta 2013 znanstvena revija za ekumensko teologijo in medreligijski dialog Edinost in dialog. 
Ob 25-letnici izida okrožnice Da bi bili eno papeža Janeza Pavla II. je papež Frančišek 24. maja 2020 napisal kardinalu Kurtu Kochu, predsedniku Papeškega sveta za edinost kristjanov, posebno pismo. Kardinal Koch pa je 5. junija 2020 ob 60. obletnici ustanovitve Tajništva (od 1988 Papeški svet) za edinost kristjanov dal intervju, v katerem je spregovoril o 25. obletnici izida okrožnice papeža Janeza Pavla II. Da bi bili eno o ekumenizmu. Papeževo pismo in intervju s kardinalom Kurtom objavljamo.

\section{Pismo Frančiška kardinalu Kurtu Kochu ob 25-letnici izida okrožnice Ut unum sint o ekumenizmu}

Dragemu bratu kardinalu Kurtu Kochu, predsedniku Papeškega sveta za pospeševanje edinosti med kristjani

Jutri bo minilo petindvajset let, odkar je sv. Janez Pavel II. podpisal okrožnico Ut unum sint. S pogledom, uprtim v jubilej leta 2000, je želel, da bi se Cerkev na svoji poti proti tretjemu tisočletju spominjala goreče molitve svojega Učitelja in Gospoda: »Da bi bili vsi eno!« (Jn 17,21) Zato je napisal to okrožnico, ki je »nepreklicno« (CD 63, št. 3) potrdila ekumensko prizadevanje Katoliške cerkve. Objavil jo je na slovesni praznik Gospodovega vnebohoda ter jo postavil pod znamenje Svetega Duha, ustvarjalca enosti v različnosti, in v tem enakem bogoslužnem in duhovnem kontekstu se je spominjamo ter jo ponovno predlagamo Božjemu ljudstvu.

Drugi vatikanski koncil je prepoznal, da je gibanje za ponovno vzpostavitev enosti med vsemi kristjani »nastalo po milosti Svetega Duha« (E, 1). Prav tako je pritrdilo, da je Duh, medtem ko »udejanja različnost milosti in služb«, "počelo enosti Cerkve« (ibid., 2). Okrožnica Ut unum sint prav tako poudarja, da »upravičena raznolikost še zdaleč ne nasprotuje enosti Cerkve, ampak povečuje njeno lepoto in nemalo prispeva k dopolnitvi njenega poslanstva« (CD 63, št. 50). „Samo Sveti Duh lahko prebudi raznovrstnost, mnogoterost in obenem ustvarja edinost. [...] On je tisti, ki daje skladnost Cerkvi«, saj je, kakor pravi sv. Bazilij Veliki, »On sam skladnost" (Homilija v katoliški katedrali Svetega Duha, Istanbul, 29. november 2014). 
Ob tej obletnici se zahvaljujem Gospodu za pot, ki nam jo je dal uresničiti kot kristjanom v iskanju polnega občestva. Tudi jaz se strinjam z zdravo nestrpnostjo tistih, ki včasih mislijo, da bi se lahko in bi se morali bolj zavzeti. Vendar pa nam ne smeta pojenjati vera in hvaležnost: $\mathrm{v}$ teh desetletjih so bili storjeni mnogi koraki za to, da bi bile ozdravljene stoletne in tisočletne rane. Povečali sta se vzajemno poznavanje in spoštovanje, kar je pripomoglo k preseganju ukoreninjenih predsodkov; razvila sta se teološki dialog in dialog dejavne ljubezni kot tudi različne oblike sodelovanja v dialogu življenja, na pastoralnem in kulturnem področju. V tem trenutku gre moja misel k mojim ljubljenim Bratom, ki so postavljeni na čelo različnih krščanskih Cerkva in skupnosti; in se širi na vse brate in sestre vseh krščanskih izročil, ki so naši sopotniki. Kakor emavška učenca lahko čutimo prisotnost vstalega Kristusa, ki hodi poleg nas in nam razlaga Pisma, ter ga prepoznamo v lomljenju kruha, ko pričakujemo, da bomo lahko skupaj pri evharistični mizi.

Ponovno se zahvaljujem tistim, ki so delovali in delujejo v tem Dikasteriju (Uradu), da v Cerkvi ohranjajo živo zavest glede tega cilja, ki se mu ne smemo odpovedati. Posebej sem vesel, da lahko pozdravim dve nedavni pobudi. Prva je Ekumenski vademekum (Vademecum ecumenico) za škofe, ki bo objavljen letos jeseni kot spodbuda in priročnik pri izvajanju njihovih ekumenskih odgovornosti. Služba za edinost je namreč eden izmed ključnih vidikov poslanstva škofa, ki je »vidno počelo in temelj edinosti« $v$ svoji delni Cerkvi: C, 23; ZCP kan. 383, \3; Zakonik prava vzhodnih Cerkva, 902-908). Druga pobuda je začetek izhajanja revije Acta Ecumenica, ki v okviru Informacijske službe Dikasterija predstavlja pripomoček za tiste, ki delajo v službi edinosti.

Na poti, ki vodi k polnemu občestvu, se je pomembno spominjati prehojene poti, pa tudi opazovati obzorje ter si z okrožnico $U t$ unum sint zastaviti vprašanje: "Quanta est nobis via?«, »Kako dolga pot je še pred nami?« (CD 63, št. 77). Ena stvar je gotova: edinost ni v prvi vrsti rezultat našega delovanja, ampak je dar Svetega Duha. Vendar pa "ne bo prišla kot čudež na koncu: do edinosti pride na poti, ustvari jo Sveti Duh na poti« (Homilija med večernicami, Sv. Pavel zunaj obzidja, 25. januar 2014). Zaupno torej prosimo 
Duha, naj vodi naše korake ter naj vsakdo s prenovljeno močjo začuti poziv, da bi delal za ekumenizem; naj On navdihne nova preroška dejanja ter okrepi bratsko dejavno ljubezen med vsemi Kristusovimi učenci, »da bo svet veroval« (Jn 17,21) in se bo pomnožila hvala Očetu, ki je v nebesih.

Vatikan, 24. maj 2020

(Prevedla s. Leonida Zamuda, Radio Vatikan)

\section{Kardinal Kurt Koch ocenjuje šestdeset let ekumenske poti v Katoliški cerkvi}

Švicarski kardinal Kurt Koch, predsednik Papeškega sveta za edinost kristjanov, je za spletni portal VaticanNews spregovoril o izzivih in napredku na ekumenski poti v Cerkvi ob šestdesetletnici delovnega telesa, ki ga danes poznamo kot Papeški svet za edinost kristjanov. Po Kochovih besedah obeležujemo spomin na dva dogodka: 25 . obletnico izida okrožnice papeža Janeza Pavla II. Da bi bili eno (Ut unum sint) o ekumenizmu in 60. obletnico Tajništva za pospeševanje edinosti kristjanov, ki ga je ustanovil papež Janez XXIII. 5. junija 1960 in ga je 28. junija 1988 Janez Pavel II. povzdignil v Papeški svet za edinost kristjanov. Obletnici sta razlog za veliko veselje. Po papeževih besedah gre za nenehno prizadevanje na poti, ki ne pozna vrnitve nazaj. Kardinal je poudaril, da ekumenizem sloni na treh stebrih, ki so: dialog ljubezni, dialog resnice in iskreno ter složno pridruževanje vseh vernikov Jezusovi velikoduhovniški molitvi, »da bi bili vsi eno«. Vsi papeži po koncilu so vztrajno in dosledno podpirali ekumenizem.

\section{Pred šestdesetimi leti je bil ekumenski kontekst povsem drugačen. Kako bi opi- sali sedanji položaj ekumenizma in današnje naloge?}

Leta 1960 je bilo ekumensko gibanje šele v povojih, če imamo v mislih njegovo uradno obliko znotraj Katoliške cerkve. V naslednjih desetletjih smo bili priča številnim srečanjem in dialogom, ki so obrodili mnoge lepe sadove. Dejanski cilj ekumenskega gibanja, ki je obnovitev edinosti Cerkve, pa vendarle še ni dosežen. Eden glavnih izzivov našega časa je ravno odsotnost trdnega soglasja o namenu ekumenizma. Strinjamo se, da je edinost potrebna, ni pa še soglasja o tem, kakšno obliko naj bi imela. 
Za edinost Cerkve je nujno potrebna skupna vizija. Naslednji koraki bodo možni, le če bomo imeli pred seboj jasen cilj.

\section{Ekumensko pot večkrat opisujejo kot »izmenjavo darov «. Kako se je Katoliška cerkev $v$ zadnjih šestdesetih letih spreminjala pri tem prizadevanju? Katere da- rove je naša Cerkev ponudila drugim kristjanom?}

V ozadju te opredelitve je prepričanje, da more vsaka Cerkev na svoj lastni način prispevati k obnovitvi edinosti. Od Cerkva in cerkvenih skupnosti, ki izvirajo iz reformacije, se je Katoliška cerkev učila zlasti tega, kako središčno mesto ima Božja beseda v življenju Cerkve, pri liturgičnih opravilih in pri teološkem razmišljanju. Poživili smo zavest, da se vera rojeva ob poslušanju Božje besede in da mora evangelij Jezusa Kristusa stati v središču Cerkve. Od pravoslavnih Cerkva se lahko marsikaj naučimo, kar zadeva sinodalnost v življenju Cerkve in zbornost škofov; to je večkrat poudaril papež Frančišek. Poudarek na univerzalnosti (vesoljnosti) Cerkve pa je tisti poseben dar, ki ga lahko k ekumenskemu razpravljanju prispeva Katoliška cerkev. Ona namreč živi v soodnosnosti (interrelazione) med edinostjo vesoljne Cerkve in mnoštvom krajevnih Cerkva. Zato more dajati zgled, kako si edinost in mnoštvo tudi pri ekumenizmu ne nasprotujeta, ampak se med seboj podpirata.

\section{Ekumenizem ima za cilj polno občestvo med vsemi kristjani. Kaj je bilo pri tem konkretno doseženo?}

Vsi ekumenski napori in dejavnosti morajo služiti obnovitvi edinosti kristjanov. Od časa do časa je treba preveriti, ali so naravnani na doseganje tega cilja. To še posebej velja za dialog ljubezni, ki pomeni skrb za ohranjanje prijateljskih odnosov med različnimi Cerkvami. Ta dialog je odpravil mnoge predsodke iz preteklosti in pomagal $\mathrm{k}$ boljšemu razumevanju. Enako pomemben je dialog resnice, to je teološko razčlenjevanje spornih vprašanj, ki so v zgodovini privedla do delitev. Pri teh razgovorih je postalo jasno, da je več tega, kar nas združuje, kakor tistega, kar nas razdvaja. Temeljnega pomena je tudi duhovni ekumenizem, ki pomeni iskreno ter složno pridruževanje vseh vernikov Jezusovi velikoduhovniški molitvi, »da bi bili vsi eno«. Molitev budi v nas zavest, da je edinost to, kar hoče Gospod. 


\section{Te dni mineva tudi petindvajset let od izida okrožnice Da bi bili eno (Ut unum sint) sv. Janeza Pavla II., ki je izšla 25. maja 1995. Kakšen je njen pomen za eku- mensko pot?}

Glavni pomen okrožnice je dejstvo, da prvič v zgodovini papež napiše okrožnico o ekumenizmu. Izšla je trideset let po koncilu. Z njo je Janez Pavel spomnil, da se je katoliška Cerkev »nepreklicno zavezala«, da stopi na pot ekumenizma (št. 3), in da vera vse člane Cerkve zavezuje k sodelovanju pri ekumenskem gibanju. Omembe vredna je še ena papeževa pobuda. Po eni strani se je zavedal, da petrovska (papeška) služba predstavlja eno večjih ovir za obnovitev edinosti. Obenem je bil prepričan, da ima služba rimskega škofa nepogrešljivo vlogo pri ohranjanju edinosti Cerkve. Zato je v okrožnici povabil celotno ekumensko skupnost, da vzpostavi »bratski in potrpežljiv dialog« o prvenstvu rimskega škofa. Namen dialoga bi bil, da se najde »takšna oblika izvrševanja prvenstva (primata), ki bo odprta za nov položaj, ne da bi se v čemerkoli odpovedali temu, kar je za njegovo poslanstvo bistveno«. Povedano drugače: poiskali naj bi »tiste oblike, v katerih bo ta služba mogla udejanjati takšno služenje ljubezni, ki ga bodo priznavali eni in drugi« (št. 95-96). Menim, da gre za obetavno pobudo, ki sta jo večkrat ponovila tudi papeža Benedikt XVI. in Frančišek.

\section{Od ustanovitve Papeškega sveta za edinost so se papeži veliko trudili za ekume- nizem. Kako bi na kratko opisali njihov prispevek?}

Predvsem moramo biti hvaležni za to, da so vsi papeži po koncilu imeli odprto srce za ekumensko stvar in da so jo vztrajno in dosledno podpirali. Papež Janez XXIII. se je dobro zavedal, da je obnovitev edinosti temeljnega pomena za prenovo Katoliške cerkve. Papež Pavel VI. je odločilno prispeval k temu, da je koncil sprejel Odlok o ekumenizmu (1964). Bil je papež velikih ekumenskih dejanj, zlasti v razmerju do pravoslavja in do Anglikanske skupnosti. Bil je prvi, ki je obiskal Ekumenski (svetovni) svet Cerkva v Ženevi. Papež Janez Pavel II. je bil prepričan, da se bo tretje tisočletje moralo spoprijeti z velikansko nalogo obnovitve izgubljene edinosti. Uvidel je, da nepogrešljivo pomoč pri tem predstavlja pričevanje mučencev, ki pripadajo različnim Cerkvam; ti so z darovanjem svojega življenja že uresničili in dosegli edinost. Za papeža Benedikta XVI. je ekumenizem na najgloblji ravni vprašanje vere in zato prvenstvena dolžnost Petrovega naslednika. Za papeža Frančiška je temeljnega 
pomena, da različne cerkvene skupnosti skupaj hodijo po poti edinosti, ker edinost raste ob tem, ko hodimo skupaj. Tudi on večkrat poudarja pomen »ekumenizma krvi«, to je mučeništva.

\section{Papeški svet bo obeležil letošnjo dvojno obletnico s tem, da bo izdal ekumenski priročnik za škofe. Kakšen namen ima novi dokument?}

Škofova služba je služenje edinosti v njegovi škofiji ter edinosti med krajevno in vesoljno Cerkvijo, pomembna pa je tudi za ekumenizem. Na škofovo pastirsko službo je treba gledati širše, ker zajema tudi tiste krščene, ki niso katoličani. Škofje imajo v krajevnih Cerkvah glavno odgovornost za edinost kristjanov. Priročnik jim želi pomagati, da bi globlje dojemali svojo ekumensko odgovornost in jo prevajali v prakso. Posebej se obrača na nedavno imenovane škofe in jih spodbuja, da pomagajo vsem članom Cerkve, da bi se mogli udeleževati ekumenskega gibanja.

Nova pobuda Papeškega sveta za to obletnico je tudi izdajanje revije ActaOecumenica; ta nadaljuje in dopolnjuje informacijski bilten (InformationService/Service d'Information), ki izhaja že nad petdeset let. Kakšen je namen te revije?

Nekateri današnji verniki imajo vtis, da je ekumenizem v zastoju. Razlog je, da niso dovolj obveščeni o napredkih in razvoju na tem področju. Zato je pomembno, da tehtnejši ekumenski dosežki pridejo do vernikov in da jih ti sprejmejo. To velja še posebej za dokumente, ki jih pripravijo in objavijo ekumenske komisije. Neprebrani dokumenti ne koristijo mnogo. Revija ActaOecumenica želi olajšati to sprejemanje. Prinaša poročila o ekumenskem prizadevanju papeža Frančiška in o ekumenski dejavnosti Papeškega sveta za edinost s tem, da objavlja glavne dokumente ekumenskih pogovorov. Revija hoče biti podpora ekumenski vzgoji in oblikovanju.

\section{Ekumenizem se dogaja ob srečanjih in razgovorih. Kako kriza ob pandemiji vpliva na vaše delo?}

Ekumenizem živi od pogovorov in neposrednih, osebnih stikov. Vse to je zaradi sedanjih omejitev težje uresničljivo. Tu v Rimu ne moremo sprejemati predstavnikov drugih krščanskih Cerkva niti ne moremo potovati k njim. Ekumenski pogovori so oteženi, ko potekajo na daljavo. Po drugi 
strani pa težaven položaj zbližuje krščanske Cerkve, ki so vse vkrcane v isti čoln. To se je pokazalo tudi minulega 25. marca, ko je papež Frančišek povabil krščanske Cerkve, da se mu pridružijo pri molitvi očenaša za konec pandemije. Papeževo vabilo sem pisno posredoval voditeljem krščanskih Cerkva, ki so se zahvalili za to pobudo. To dokazuje, kako so se v tem času poglobili ekumenski odnosi in kako se lahko v težavnih situacijah še okrepijo. Tem bolj bomo veseli, ko se bomo mogli spet srečati in se pogovarjati osebno.

Tudi vi, eminenca, boste kmalu praznovali obletnico, saj vas je 1. julija 2010 papež Benedikt XVI. imenoval za predsednika Papeškega sveta za edinost kristjanov. Kakšen je po vašem mnenju izkupiček teh let?

Kako hitro je minil ta čas! Moje delo ni vedno lahko, a je zelo lepo in me bogati. Hvaležen sem papežu Benediktu XVI., da mi je zaupal to nalogo, in papežu Frančišku, da me je v tej službi potrdil. V teh letih sem se udeleževal različnih ekumenskih dogodkov in pobud obeh papežev in pri njih sodeloval. Veliko sem se naučil in večkrat doživel, da pri ekumenskem delu prejmeš več, kakor lahko daš. Zavedam se, da obstaja v jedru en sam ekumenski minister, to je Sveti Duh. Tako imenovani ekumenski delavci smo samo bolj ali manj nebogljeno orodje. Po desetih letih še ni čas, da bi delal obračun. Ta skromna obletnica pa je lepa priložnost, da se zahvalim Svetemu Duhu in ga prosim, da še naprej spremlja ekumensko pot in nam omogoči, da napravimo prave korake, ki nas bodo približali edinosti Cerkve.

(Prevedel Bogdan Dolenc) 


\section{Kratice}

CD Cerkveni dokumenti

E Odlok o ekumenizmu (Unitatis redintegratio)

EZ Ekumenski zbornik

ZCP Zakonik cerkvenega prava

\section{Reference}

Dolenc, Bogdan. 1995. Okrožnica Da bi bili eno in apostolsko pismo Luč Vzhoda dva pogumna in preroška dokumenta o edinosti. Vedinosti 50: 11-25.
Kasper, Walter. 2005. Odlok o ekumenizmu. Novo branje po štiridesetih letih. Vedinosti 60: 73-87. 